This item was submitted to Loughborough's Research Repository by the author.

Items in Figshare are protected by copyright, with all rights reserved, unless otherwise indicated.

\title{
Experimentation at the interface of fluvial geomorphology, stream ecology and hydraulic engineering and the development of an effective, interdisciplinary river science
}

\section{PLEASE CITE THE PUBLISHED VERSION}

http://dx.doi.org/10.1002/esp.1838

\section{PUBLISHER}

(c) John Wiley \& Sons, Ltd.

\section{VERSION}

SMUR (Submitted Manuscript Under Review)

\section{LICENCE}

CC BY-NC-ND 4.0

\section{REPOSITORY RECORD}

Rice, Stephen P., Jill Lancaster, and Paul Kemp. 2019. "Experimentation at the Interface of Fluvial Geomorphology, Stream Ecology and Hydraulic Engineering and the Development of an Effective, Interdisciplinary River Science". figshare. https://hdl.handle.net/2134/13028. 
This item was submitted to Loughborough's Institutional Repository (https://dspace.lboro.ac.uk/) by the author and is made available under the following Creative Commons Licence conditions.

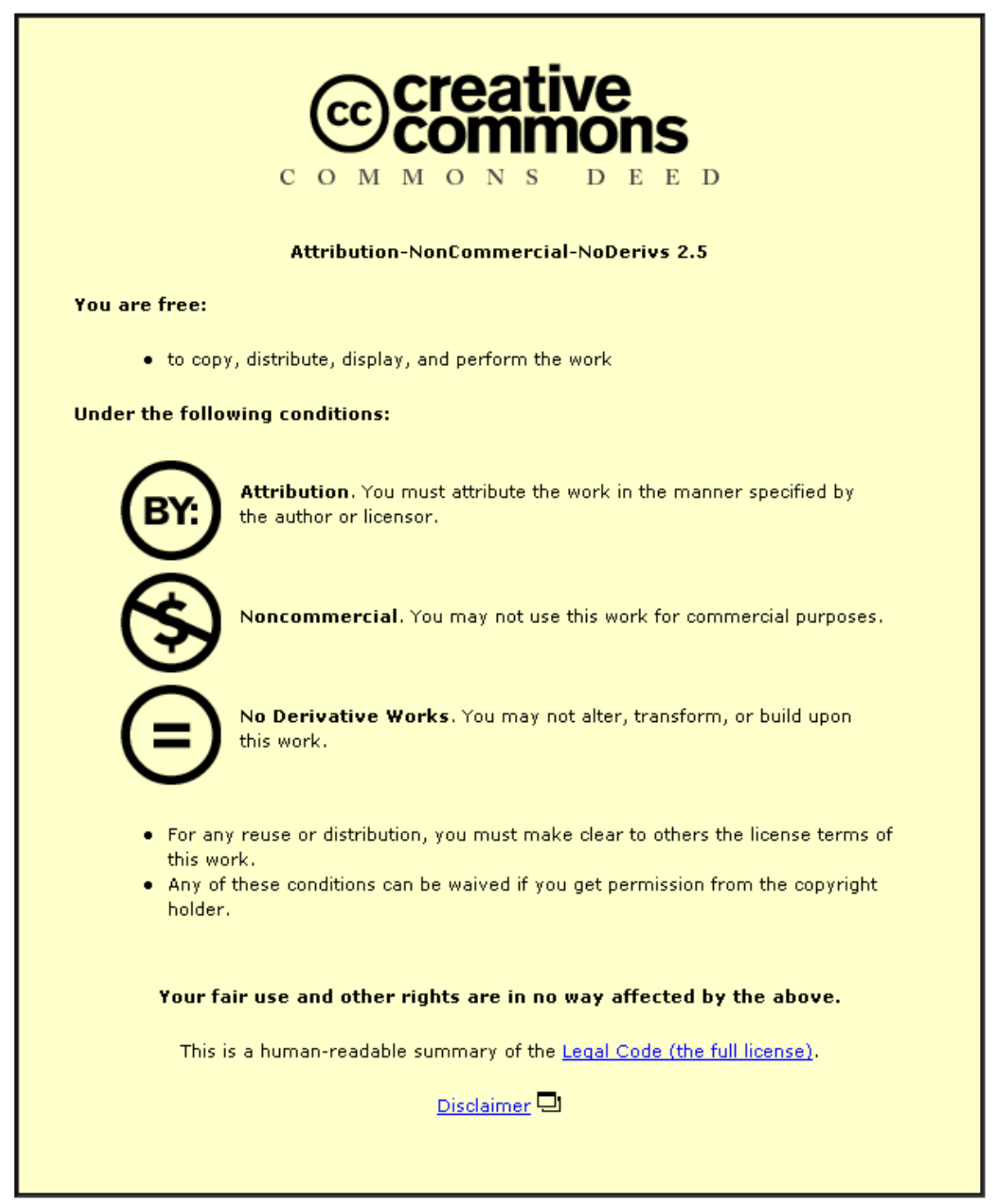

For the full text of this licence, please go to: http://creativecommons.org/licenses/by-nc-nd/2.5/ 


\section{Experimentation at the interface of fluvial geomorphology, stream ecology and hydraulic engineering and the development of an effective, interdisciplinary river science}

Short title: Interdisciplinary experiments and integrated river science

Stephen P. Rice ${ }^{1}$, Jill Lancaster ${ }^{2}$ and Paul Kemp ${ }^{3}$

1 Department of Geography, Loughborough University, Leicestershire, LE11 3TU, UK (corresponding author)

2 Institute of Evolutionary Biology, University of Edinburgh, Ashworth Labs, West Mains Road, Edinburgh, EH9 3JT, UK

3 School of Civil Engineering \& the Environment, University of Southampton, Highfield, Southampton, SO17 1BJ, UK

\section{Correspondence to:}

Stephen Rice, Department of Geography, Loughborough University, Leicestershire LE11 3TU, UK

email: S.Rice@lboro.ac.uk 


\section{Abstract}

One "2020 vision” for fluvial geomorphology is that it sits alongside stream ecology and hydraulic engineering as a key element of an integrated, interdisciplinary river science. A challenge to this vision is that scientists from these three communities may approach problems from different perspectives with different questions and have different methodological outlooks. Refining interdisciplinary methodology is important in this context, but raises a number of issues for geomorphologists, ecologists and engineers alike. In particular, we believe that it is important that there is greater dialogue about the nature of mutually-valued questions and the adoption of mutually-acceptable methods. As a contribution to this dialogue we examine the benefits and challenges of using physical experimentation in flume laboratories to ask interdisciplinary questions. Working in this arena presents the same challenges that experimental geomorphologists and engineers are familiar with (scaling up results, technical difficulties, realism) and some new ones including recognising the importance of biological processes, identifying hydraulically meaningful biological groups, accommodating the singular behaviour of individuals, understanding biological as well as physical stimuli, and the husbandry and welfare of live organisms. These issues are illustrated using two examples from flume experiments designed (1) to understand how the movement behaviours of aquatic insects through the near-bed flow field of gravelly river beds may allow them to survive flood events, and (2) how an understanding of the way in which fish behaviours and swimming capability are affected by flow conditions around artificial structures can lead to the design of effective fish passages. In each case, an interdisciplinary approach has been of substantial mutual benefit and led to greater insights than discipline-specific work would have produced. Looking forward to 2020, several key challenges for experimentalists working on the interface of fluvial geomorphology, stream ecology and hydraulic engineering are identified. 
Key words: flume experiments, ecohydraulics, macroinvertebrates, refugia, fish passage 


\section{Introduction}

The fascinating scientific arena in which fluvial geomorphology and river hydraulics meet stream ecology is of growing strategic as well as academic interest. Fluvial geomorphologists and hydraulic engineers recognise the importance of in-stream and riparian ecological processes for understanding sediment fluxes, water flow and landforming processes at a variety of scales (e.g. Millar, 2000; Gottesfeld et al., 2004; Buttler and Malanson, 2005; Cotton et al., 2006; Johnson et al., in press). Equally, ecologists have long recognised the importance of open-channel hydraulics, sediment stability and the other processes that provide and maintain channel morphology, for understanding the distribution and behaviour of aquatic organisms (e.g. Minshall, 1984; Newbury, 1984; Statzner et al., 1988; Hart and Finelli, 1999; Lancaster, 2008). Research at this interface is not new; ecologists and biologists have been interested in physical-biological coupling in streams for 100+ years, as indicated by early work on insects (Steinmann, 1907; 1908) and on fish (Hora, 1922). However, scientific and methodological advances in recent decades have lead to disciplinary specialisation and polymaths are becoming rare, so future research in this field is likely to be carried out by collaborative teams rather than by individuals.

There is widespread recognition that such interdisciplinary effort is likely to yield substantial benefits (e.g. Palmer and Bernhardt, 2006), but it is also apparent that truly interdisciplinary research remains relatively rare (e.g. Bond, 2003; Hannah et al., 2004; 2007) and is difficult to achieve, in part because it represents "an evolution in the conduct of science” (USGS/ESA, 1998). The general challenges of integrating disciplines in which language, theory and methodological practice have evolved independently are reviewed elsewhere (e.g. Naiman 1999) and we will not reiterate those arguments here. It is sufficient to say that scientists from hydraulics, geomorphology and ecology often approach problems from different perspectives, 
with different ways of defining questions and deciding upon appropriate research methods (e.g. Benda et al., 2002; Nestler et al., 2007). Too often, therefore, the disciplines operate in a parallel, multidisciplinary mode rather than in an integrated, interdisciplinary mode to address questions of mutual scientific interest.

In this case, a significant risk, amongst others, is that researchers fail to recognise the limits to their own expertise: an ecologist in possession of a flow meter is no more qualified to test cutting-edge hypotheses about near-bed turbulent structures than a hydrologist able to identify a mayfly is necessarily capable of identifying meaningful questions about population dynamics. As an example of weak interdisciplinary logic, consider the widespread assumption that habitat association models (HAMs), such as habitat suitability or flow preference curves, can be used to predict the density of species at a site and how changes in density might follow changes in the environment. This assumption is not supported by ecological theory (e.g. Anderson et al., 2006), the statistical descriptions of HAMs are often incorrect and lack any causal basis (Lancaster and Belyea, 2006; Lancaster et al., in review a) and, thus, predictions based on HAMs may be wrong. Further, freshwater studies involving HAMs are carried out typically on a single, freshwater life stage whereas most freshwater species have complex life cycles (e.g. insects have aquatic larvae and terrestrial adults; many fish are migratory and occupy both marine and freshwater habitats, or lotic and lentic habitats) so that the factors setting population density may be unrelated to events in the stream (Welch, 1976; Lancaster et al., in review b).

The need for clarity about the questions, scientific problems and hypotheses that would benefit from collaborative research is perhaps even more prominent than the need to develop common methodologies. This is true, not only for improving our "blue-skies" knowledge of river systems, but also for providing the robust scientific understanding necessary to support 
sustainable river management (Palmer and Bernhardt, 2006). That there are still many questions to answer and much to learn is illustrated by the inconsistent ecological impact of one of the most widely adopted river restoration practices - the placement of physical structures (wood or boulders), ostensibly to improve in-stream habitat by increasing physical heterogeneity (see Thompson and Stull, 2002 for a historical perspective). Some placement schemes are associated with ecological improvements (e.g. Riley and Fausch, 1995; Van Zyll de Jong et al., 1997; Roni and Quinn, 2001), while others show no obvious benefits (e.g. Olson and West, 1989; Bjornn et al., 1991), and some fail entirely (Frissell and Nawa, 1992). This inconsistency reflects a range of potential problems, most fundamental of which is that most rehabilitation or restoration efforts are largely disconnected from ecological theory (Palmer et al., 1997; Lake et al., 2007). The expectation that streams can be “improved” by simply altering the physical environment, i.e. the Field of Dreams hypothesis: if you build it they will come (Palmer et al. (1997), is unfounded because population density at a site and the potential for density to increase may be determined by many different processes, including dispersal distance and ability, barriers to dispersal, large-scale or long-term disturbance, factors affecting life stages that inhabit non-freshwater habitats (as above), species interactions, etc. Therefore, while there is some evidence that altering the physical environment can assist rehabilitation, ecological responses are likely to be complex. For example, physical structures may be beneficial for drift-feeding predatory fish because fish can occupy low energy positions behind structures close to swift-flowing, food-laden currents (Jenkins, 1969; Everest and Chapman, 1972; Fausch and White, 1981) and because increased turbulent mixing may increase prey encounter rates (MacKenzie and Kiorboe, 1995; Lewis and Pedley, 2001) but, conversely, complex habitats can also be associated with lower rates of food acquisition (Crowder and Cooper, 1982; Savino and Stein, 1982; Diehl, 1988). In recent experiments that compared the behaviour and performance of juvenile salmon parr in high 
and low complexity habitats, foraging was significantly compromised in the "complex" treatment, yielding lower rates of growth and lipid deposition (Kemp et al., 2006), possibly because enhanced structural complexity impeded the parr's field of view. This example highlights the need to consider the full range of potential ecological responses and interactions to altered abiotic parameters and the continued need for fundamental interdisciplinary research to elucidate how physical and biological factors interact.

In sum, research progress at the biological-physical interface is increasingly dependent upon collaborations among individuals with appropriate expertise in different disciplines. While the case for interdisciplinary research may be well founded, the challenge now is to maximise effectiveness in these collaborations by encouraging a cumulative, integrated approach based on answering mutually-valued research questions. Our intention in this essay is not to reiterate the argument for an interdisciplinary river science, but rather to support the development of such a science by contributing a discussion about the nature of mutually-valued questions and the adoption of mutually-acceptable methods. Looking forward to 2020 and the "vision of geomorphology” that this special issue is concerned with, we believe that a dialogue about relevant questions and methods is important for the development of an integrated river science. The range of methods for addressing questions at the geomorphology-ecology interface is diverse including surveys or descriptive studies, manipulative experiments in the field or laboratory, and numerical or simulation models. Here we focus on experimental studies in laboratory flumes utilising macroinvertebrates and fish, because they illustrate several issues that may be of general relevance in other areas of the interdisciplinary field and because flume experimentation is valued by all three disciplines. First, we consider three issues that are of general concern when conducting flume experiments with small animals: realism, simplification and scale; species diversity and generality; and flume facilities and instrumentation. Next, we present two examples of interdisciplinary research, discussing the 
questions that motivated the research, the rationale behind the choice of methods, and the results. Finally, we discuss some of the key issues and challenges for interdisciplinary flume experiments in future.

\section{General Considerations for Interdisciplinary Flume Experiments}

\section{Realism, simplification and scale effects}

The primary strength of flume studies is, of course, the ability to control some variables and manipulate others, i.e. the classical manipulative experiment. One particularly exciting aspect of interdisciplinary work is the opportunity to independently manipulate physical and biological parameters in order to understand their relative influence on animal behaviour or processes. This may include working with both living and dead organisms in order, for example, to disentangle behavioural and mechanistic effects on drift distance (Ciborowski and Corkum, 1980; Allan and Feifarek, 1989; Oldmeadow, 2005).

This strength is also a significant drawback, however, as simplifications are always at the cost of realism. A substantial problem for ecologists is that flumes are unnatural environments and animals in flumes always behave unnaturally in some respects. This includes responses of organisms to the simplified physical environment of the flume, to the presence of measurement instruments, to the physicochemical environment (e.g., temperature, dissolved oxygen, water chemistry), and to the simplified biotic environment, including changes in (or lack of) food resources, competitors, predators, etc. A few studies have recorded how animals respond to artificial flume environments (e.g. Barmuta et al., 2001) and critical evaluations of how test conditions affect behaviour should be routine, even though it may be impossible to eliminate such biases completely or derive a correction factor of any sort. Overall, the 
challenge is to minimise the stresses and try to ensure that any behaviour modifications do not compromise the study objectives, interpretations and inferences. The potential for stress also exists when animals are collected from their natural environment, transported to the laboratory and held until experiments begin, and this also must be minimised in order to avoid compromising the experiment. It is because these challenges are so daunting, and likely to be insurmountable in many cases, that ecologists favour manipulative field experiments and methods that allow in situ observations using instruments such as endoscopes (Wilzbach, 1990) and underwater cameras (Sharpe, 2002; Davidsen et al., 2005). In rivers, control over the physical environment may be poor and experimental manipulations so coarse as to horrify most hydraulicists, but there is much less concern about the "naturalness” of organisms' responses and far more confidence in the ecological inferences and interpretations.

Of course, these concerns also extend into the physical realm. Manipulative field experiments are valued (e.g. Oldmeadow and Church, 2006) but relatively less common in geomorphological research (Slaymaker, 1981), which has favoured the use of flumes and sand tables in experimental studies of fluvial processes, with attendant questions about the degree of realism that is appropriate. For example, in experimental studies of flow around gravel bedforms, compare the representation of pebble clusters in groundbreaking work by Brayshaw et al. (1983) as simple, hemispherical bluff bodies and the subsequent use of carefully reproduced “natural” pebble clusters by Lawless and Robert (2001b). The more highly abstracted representations can be parameterised more easily and may yield results that lend themselves to the construction of simplified statistical or numerical models describing the key features of a phenomenon, whereas examination of fuller complexity brings greater understanding of the natural situation (or at least a restricted subset of it) but aspects of the results may be of uncertain transferability and therefore less predictive utility. Which 
elements are controlled and manipulated and what level of abstraction depends upon the primary aims of the research.

Even though flume work with many species of macroinvertebrate and fish can be at or close to prototype scale (that is, the physical environment is not a scaled version of reality), the limited size of most flume facilities nevertheless restricts realism because in all but the biggest flumes the spatial domain is constrained. The physical environment that animals experience is therefore limited in terms of its absolute spatial extent and 2D complexity (patchiness), both of which are integral to many of the ecological processes that drive population and community-level phenomena. Spatial patchiness is an equally important element of physical river processes (e.g. Paola and Seal, 1995; Buffington and Montgomery, 1999) that remains difficult to accommodate in flume experiments. More generally, if experiments that include live organisms are conducted at less than prototype scale, there is the potential for geometric, kinematic or dynamic scale effects to influence experimental observations. While engineers and geomorphologists traditionally apply similarity principles to minimise these effects (Novak and Cábelka, 1981; Ashmore, 1991; Ashworth, 1996), these principles do not extend to the incorporation of live organisms. The challenges of ensuring consistency between model and prototype that are apparent in purely physical experiments (e.g. Peakall et al., 1996) and that are substantially increased in experiments that involve living plants (cf. Tal and Paola, 2007), are amplified further by the inclusion of living animals. Indeed, achieving sensible scale similarities may be intractable because identifying a scale version of the live subject organism that retains equivalent morphological and behavioural characteristics is not possible. Moreover, while Froude rather than Reynolds scaling is usually prioritised in models of open channel flow, any manipulation of fluid properties such as water temperature to minimise viscous effects and achieve sensible turbulent conditions (e.g. Southard et al., 1980), is likely to have a profound effect on 
organism behaviour and survivorship. This does not imply that all interdisciplinary experiments must be at prototype scale to be valuable, because much can be learned from heavily distorted or entirely unscaled experiments, rather it implies that scaling issues require careful consideration.

In experiments that consider both biological and physical elements, the familiar problem of deciding which elements of the environment to exclude or include, and how realistic or idealised to make the included elements, must encompass physical and biological elements. Issues of scale impinge upon this decision making. Trying to include appropriate biological elements in inappropriate physical conditions or vice versa is unlikely to yield mutually satisfying data. This is why an engineer with an appreciation of wall effects and boundary layer development may be sceptical of biological experiments conducted in flumes with low width to depth ratios or very short test sections. Nowell and Jumars (1987) recommended that flumes for use in biological experiments should have a width to depth ratio of at least 5 to 1 in order to reproduce realistic boundary layers. In a recent review, Jonsson et al. (2006) concluded that the ratio between the width of the flume and the wall boundary layer thickness $(\delta)$ is a more important consideration, recommending that flume width should exceed $2 \delta+\mathrm{k}$ where $\mathrm{k}$ is a relevant length scale of the organism under investigation. Similarly, an ecologist aware of the diel activity and light sensitivity of aquatic insects may question the value of examining the movements of negatively phototactic species on flume beds that are brightly lit or lacking shelter (Barmuta et al., 2001). Creating suitably realistic environments within flumes, thus, is likely to remain a substantial challenge that requires input from each party in order to ensure the most sensible, mutually beneficial compromise. Equally, we must accept that some hypotheses will simply be untestable in flumes. 


\section{Species diversity and generality}

Flume studies can only ever examine one or a few species of organism - a small subset of the 10s-100s of species of macro-organism that are typically found in a single stream community, and a smaller subset of the world's species richness $\left(10^{5}-10^{6}\right.$ species of aquatic insect alone). Even among species that are closely related taxonomically, there can be stark differences in physiology, morphology and behaviour that influence their responses to hydraulic environments. While there is merit in targeting a single species for intensive research - the "lab rat" approach - the risk is that we remain ignorant of the variation that inevitably exists among species. How, then, do we extrapolate or generalise from the responses of the few to the potential responses of the many? This is a question that is of less concern to geomorphologists and engineers because the physical phenomena of interest (e.g. mobile sediment particles) may vary in important ways, but the influence of the characteristics that distinguish between them (e.g. size, shape, density) on their responses to external forcing (e.g. to local shear) are better understood and relatively easily parameterised.

There have been some attempts to improve generality by classifying organisms according to their "traits" or adaptations for life in flowing water (e.g. Rader, 1997). This approach is fraught with difficulty, however, as most associations between traits and functions are based on assumptions or tenuous evidence at best, instead of rigorous empirical studies. As any one trait could serve multiple functions, classification without evidence is risky. For example, consider the oft cited case that dorso-ventral flattened bodies of benthic invertebrates can reduce drag and lift, thus allowing individuals to maintain position in fast flows; an idea first proposed by Steinmann (1907; 1908), but criticised by many (e.g. Nielsen, 1951). While drag and lift may indeed be reduced for some dorso-ventrally mayflies in fast flows, especially in the family Heptageniidae (Statzner and Holm, 1982; Weissenberger et al., 1991), other species of this same family and with the same body shape are most abundant in slow flows 
(Lancaster and Belyea, 2006) and, once entrained in turbulent flows, their ability to regain the substrate can be poor (Oldmeadow, 2005). A dorso-ventral flattened body form may be an adaptation for many different functions such as squeezing into narrow crevices (Dodds and Hisaw, 1924; Vogel, 1981) or, for perhaps the flattest of all mayfly larvae, it may offer protection against predation (Hynes, 1970). The important point is that any attempt at traitbased classification schemes will be problematic until we can be certain what functions are (or are not) served by particular traits, and this may require many more empirical studies. So, while we recognise that there is a real need to be generalise given the diversity of life, we caution against premature or unfounded generalisations.

\section{Flume facilities and hydraulic measurements}

Rarely are flumes designed and constructed to meet the needs of an individual experiment and relatively few facilities are designed specifically with interdisciplinary studies in mind. Instead, flumes tend to reflect the needs of a wide range of potential research projects and experiments then have to be designed pragmatically to take into account the limitations of the flume facility. Jonsson et al., (2006) recently made a direct comparison of a selection of facilities with the aim of identifying those flumes best suited to the study of benthos-flow interactions in marine environments. In general, however, we are unaware of attempts to define facility protocols or best-practice procedures.

Through-flow flumes that utilise natural river water are particularly useful for long-term studies of fish behaviour and performance because water quality is relatively constant. Appropriate filtration is needed if low quality (e.g. after a pollution event) or turbid (e.g. after a spate) water or natural food is to be prevented from entering the experimental channel. In many cases, the potential to attain high test velocities is limited for through-flow flumes. This 
contrasts with the high velocities that can be achieved using traditional re-circulatory flumes commonly used by hydraulic engineers. Such flumes often have powerful centrifugal pumps that drive large volumes of water at high velocities aided, in many cases, by the capability to tilt the channel. Challenges associated with these types of facility, however, often relate to the maintenance of good water quality and constant temperature (pumps will heat the water over the course of a test). In some behavioural tests, the continuous recirculation of chemical cues (e.g. Griffith and Armstrong, 2000) produced by conspecific fish may be considered a confounding variable.

Making sufficiently detailed hydraulic measurements is also a significant challenge when working with small animals. In general an appropriate aim is to acquire spatially distributed information at relatively high resolution, ideally at scales similar to those of the length scale of the organisms under investigation. For small animals the practical challenge of collecting such data is substantial, especially where the focus is not on hydraulics in the immediate vicinity of an animal but the animal's interaction with a hydraulic domain that is many times, perhaps orders of magnitude, larger than the animal. Point sampling on large grids, for example using acoustic Doppler velocimeters (ADVs), can yield very useful information but is also labour-intensive and time-consuming. For example, in the invertebrate experiments described below a grid of 440 positions was sampled using an ADV for nine experimental treatments yielding close to 4000 one-minute time series that took several months to collect.

Particle Image Velocimetry (PIV) techniques provide suitably high-resolution information relatively more rapidly but present other technical challenges (e.g. imaging laser sheets close to very rough 3D beds) and, if animals are present during flow measurements, there are additional concerns, not least the potential for inappropriate seeding materials and laser parameters to have adverse behavioural effects, cause tissue damage or death. Stamhuis et al. 
(2008) provide a detailed discussion of the many practical problems associated with using PIV with live organisms and also the substantial gains that PIV has provided in understanding animal-generated flows. An alternative to extensive direct measurements is to utilise numerical modelling, specifically Computational Fluid Dynamics (CFD) calibrated against coarsely distributed measurements, but this also remains challenging; for example where boundary roughness is complex (Lane et al., 2004).

\section{Research questions (and some answers)}

In this section, we present two examples of research at the ecologyhydrology/geomorphology interface where flume experiments have been used successfully in interdisciplinary research. By “success” we mean that significant advances were made by each constituent discipline, as well as addressing an important scientific question at the interface, i.e. the total is more interesting than the sum of the parts. Inevitably, research questions may originate in one discipline, but progress eventually requires collaboration. For each example, we provide a description of the research problem, discuss the methodological challenges and approaches taken, describe some key findings, and consider some of the problems that still remain to be addressed.

\section{How do flow disturbances (floods) affect stream invertebrate populations?}

For animals living in streams, there is a long-standing view that population densities are set by juvenile mortality, especially from predation (Peckarsky et al., 2008) and hydrologic disturbances, i.e. floods and droughts (Lake, 2000). Measuring invertebrate mortality directly is very difficult, but decreases in density before and after floods are presumed to result from 
mortality through dislodgement and current-assisted emigration, physical abrasion, burial, etc. (Death, 2008). Invertebrate densities may be reduced, especially after large floods (Giller et al., 1991; Matthaei et al., 1997), but many populations do persist in streams subject to frequent floods so clearly there are ways to reduce mortality and emigration. These observations have led to the suggestion that the spatial and temporal heterogeneity of stream environments may allow species to exploit flow refugia to survive the stresses that accompany floods. There are many kinds of flow refugia and many different ways in which they can be exploited (Lancaster and Belyea, 1997). Of interest here are the in-stream or within-habitat refugia: places within the stream channel that maintain relatively low hydraulic forces during floods and, hence, these are places where animals may survive during floods, and from which they may subsequently disperse to recolonise all areas of the stream bed. Field surveys have determined that potential flow refugia do exist naturally in streams (Lancaster and Hildrew, 1993; Palmer et al., 1996; Rempel et al., 1999) and that there are short term movements of invertebrates into (and out of) refugia in response to individual floods (e.g. Lancaster and Hildrew, 1993; Lancaster, 2000). The difficult question, which remains unanswered, is how do animals find refugia? For animals that move by walking/crawling over the stream bed, addressing these questions requires that we examine animal movements at small scales, and examine how those movements are influenced by the bed topography and the local hydraulics produced by patchy gravel-bed textures. Do their movement behaviours change in response to increased discharge and what are the consequences of these changes, e.g. do movements lead them into refugia?

The issues of how near-bed flows interact with rough, patchy, gravel substrates and how such flow characteristics are affected by changes in discharge and relative depth are of substantial geomorphological, sedimentological and hydraulic interest too. Most studies on the effects of gravelly roughness on river flow have focused on the vertical velocity profile and 
parameterisation of flow resistance terms (e.g. Ferguson, 2007). Explicit examination of spatial and temporal variability in flow above natural gravel beds (rather than idealised rough beds, e.g. Nowell and Church, 1979) is rare (e.g. Clifford, 1996). This is especially true at the patch scale $\left(10^{0}-10^{1} \mathrm{~m}^{2}\right)$ between the scale of individual bedforms (e.g. Lawless and Robert, 2001a) and the river reach (e.g. Lamarre and Roy, 2005). Of particular concern, is our limited understanding of flow in the "inner zone” (Kirkbride,1993), "roughness layer” (Raupach et al.,1991) or "interfacial and form-induced sublayers" (Nikora et al., 2007); that is, in the nearbed region extending from just above the roughness tops down to the base of the roughness troughs, where hydraulics are dominated by the local interaction of the flow with complex grain roughness. This is despite a general understanding that the spatial and temporal heterogeneity of hydraulic forces in this region are important for the dynamics of sediment transport and the formation of bed forms, and that this region is where skin friction and form drag contribute to the momentum balance and where some turbulent flow structures are generated. For these reasons, pertinent research questions for geomorphologists, hydraulicists and sedimentologists, surround the spatial and temporal variability of local flow conditions close to natural, water-worked substrates, and the effects that different substrate characteristics and general flow levels have on these patterns.

So, the question about the dispersion and movement of macroinvertebrates across patchy, rough substrates under different flow conditions is of substantial ecological interest, but the hydraulic and sedimentological information needed to investigate this issue is independently valuable too. What follows is a brief consideration of the methodological challenges and beneficial outcomes that emerged from an interdisciplinary attempt to tackle these questions (Buffin-Bélanger et al., 2003; Lancaster et al., 2006; Rice et al., 2007; Todd-Burley, 2007). 


\section{Methodological issues}

Observing, in situ, what small stream invertebrates do is challenging at the best of times, but impossible in swollen, turbid rivers. Similar problems exist for in situ examinations of small scale hydraulics in gravel-bed rivers, especially at high flows. Thus, the only real option, is to tackle these questions in a flume study.

The first challenge was to create a physical model with a realistic gravel bed surface. Ecological studies of invertebrate movement-flow interactions often use simplified substrata or randomly arranged gravels (e.g. Holomuzki and Biggs, 1999; Lancaster, 1999), but these are poor replicas of water-worked surfaces due, for example, to differences in particle packing (Kirchner et al., 1990; Nikora et al., 1998). The topography and local hydraulics of these unnatural surfaces are likely to differ from those normally experienced by invertebrates and, thus, it is impossible to know whether animal behaviours are natural. Creating water-worked surfaces within a flume, however, is difficult for all but the smallest of particles as this requires transport rates greater than can routinely be created. Previous hydraulic studies have attempted to reconstruct (Young, 1992), import (Buffin-Bélanger, 2001) or reproduce (Lawless and Robert, 2001) natural gravel textures in flumes but, until recently, such techniques had not been used in ecological studies. The solution adopted in the work described here was to use a novel casting technique to produce facsimiles of water-worked fluvial sediments with roughness properties that are the same as those of natural gravel beds (Buffin-Bélanger et al., 2003). In order to examine the effect of gravel patch texture on nearbed flows and thence insect movement, several casts of patches with contrasting sedimentological characteristics were produced These casts were placed in a $0.9 \mathrm{~m}$ wide underfloor flume, where detailed measurements could be made of the near-bed hydraulics and animals could be observed moving across the cast surfaces. 
The second challenge was deciding how to sample hydraulics in the near-bed region of each cast. Multiple planimetric positions were required in order to characterise spatial variability and patterns, ADV measurements $(60 \mathrm{~s}, 25 \mathrm{~Hz})$ were made at 110 sampling locations across a regular grid with spacing dimensions similar to the median bed particle diameter. To characterise the flow experienced by insects and bed load particles, measurements were made very close to the boundary at each location (0.008 $\mathrm{m}$ above the surface). This presented some technical and data quality issues that were dealt with by rigorous post-processing and validation of the acquired time-series (see Buffin-Bélanger et al., 2006). In addition, to understand more about the vertical extent of the near-bed flow region, measurements were made at three additional elevations at each planimetric location. In contrast to most previously published work, these positions were at fixed heights above the local bed surface, not in common subparallel planes measured above a single, global datum. This sampling scheme yields information about flow in convoluted layers that track the bed surface topography. Although data of this kind has been used to examine flow over large 2D bedforms (e.g. Smith and McLean, 1977; McLean et al., 2007) it has not been used before above complex gravel surfaces. As with the casting procedure, it is an aspect of the work that is driven by interdisciplinary motivations that has provided some unique insights that a purely hydraulic focus may not have identified. It was advantageous in this case because: (1) the alternative framework would require an impracticable number of closely-spaced planes to capture nearbed information across the whole cast surface; and (2) all measurements in a given layer are the same distance from the bed surface so spatial comparisons between different planimetric locations are not confounded by elevation differences.

The third set of challenges relates primarily to the animals. Late instars of a common cased caddisfly, Potamophylax latipennis, were used in these studies (Lancaster et al., 2006; Rice et al., 2007) because they were large-bodied and moved slowly enough that their movements 
across the cast could be recorded on a video camera suspended above the flume. Smaller and faster moving species such as baetid mayflies, would have been impossible to observe. Using a common species with an abundant population nearby, was expedient as many individuals were required to ensure adequate replication and ensure that each animal was used in only one trial (i.e. replicates have to be independent and animal behaviour can change with experience). To maximise the likelihood that animals responded primarily to the physical environment and to minimise the likelihood of any biologically motivated movements such as foraging, each subject was well-fed before introduction and trials were limited to 30 minutes.

\section{Results, outcomes and observations}

A summary of the caddis movements, as presented in Lancaster et al. (2006) and Rice et al. (2007), is as follows. Crawling was the dominant form of movement of cased caddis on these casts and only at high discharge did advective movement (saltation rather than drift as individuals tumbled over the substrate surface and were not suspended in the water column) start to become significant. Crawling paths were non-random and closely related to local micro-topography and hydraulics. Animals tended to crawl around particles rather than over the top and crawling activities were concentrated in corridors on the lee side of imbricate pebble clusters, suggesting that animals were exploiting hydraulically sheltered pathways. In contrast, there was virtually no movement onto the exposed upstream faces of the largest cobbles. Caddis crawled most frequently in low-lying areas where velocities and turbulent kinetic energies were relatively low, and occurred rarely or became entrained where flows were much higher. In general, animals avoided areas of the cast where the energetic costs of fluid drag and the risk of entrainment were high, as might be expected (Vogel, 1981). Movement was, however, contingent upon discharge. Crawling caddis selected areas of 
relatively low velocities and turbulence, and the strength of this discrimination increased with discharge. Similarly, as discharge increased, caddis crawled more slowly and shorter distances, with a corresponding decrease in rate of population spread across the stream bed.

That caddisflies crawl ineffectively at high flow may be unsurprising, but empirical data to demonstrate this phenomenon are scarce. In the context of floods and flow refugia discussed above, the results suggest that the ability of Potamophylax latipennis to crawl into refugia is lower during hydrological disturbances than during more benign conditions. In other words, individuals of this species are unable to "run for it” during floods. For populations to persist in flood-prone streams might then depend upon one of three strategies: individuals occupy refugium-type areas most of the time (Robertson et al., 1995); populations inhabit only streams that have many small, scattered, refugia so that refugia are always within each reach (Lancaster, 2000); or population birth rates are so high that enough individuals are able to survive to adulthood and produce the next generation.

Interestingly, despite the discharge-contingent behaviours, the pathways commonly used by caddis were used at all discharges and these pathways corresponded with consistent patterns in the spatial organisation of local flow. For example, patterns of relative velocity were remarkably similar at different discharges. It therefore is reasonable to presume that crawling is associated with particular sites, despite changes in local hydraulics caused by increased discharge, because certain sites consistently present the same relative hydraulic opportunities in terms of energy conservation and risk-aversion.

In addition to these insights about insect movement and refugia use, the experiments provided unprecedented high-resolution descriptions of near bed flow heterogeneity above gravelly beds formed by natural fluvial processes albeit for small areas (Buffin-Bélanger et al., 2006; Rice et al., 2007). For one apparently texturally homogeneous patch, the spatial variability of 
time-averaged velocities and flow orientations increased with gross discharge (parametrised by Reynolds number) and decreased with height above the local bed. Streamwise velocity became spatially homogeneous at a height above the local bed between two and four times the median bed elevation. The spatial variability of turbulent kinetic energy increased with gross discharge and maxima occurred in zones of intense vortex shedding in the lee of obstacle crests. These data provide a baseline empirical description that future work will build on. Simple regression models were developed to describe the dependence of the spatially averaged mean response and spatial variability of flow parameters on flow Reynolds number and local elevation above the bed (Buffin-Bélanger et al., 2006). These may prove to be valuable for predicting the patch-scale variability of near-bed hydraulic parameters using less detailed, field measurements (e.g. one or two velocity measurements above a patch). Such information is useful where spatially distributed hydraulic information is required but is seldom available; for example in order to develop our understanding of particle entrainment and sediment transport from gravel beds.

So far, caddis movements and detailed flow characteristics have been analysed on one cast only, and we do not yet know whether or how near-bed hydraulics and caddis movement varies with sediment texture. If movements are contingent upon bed texture, and very preliminary analyses suggests that this may be the case, then the next important step will be to examine movement behaviours at the interface between patch textures and to investigate (perhaps using simulation models) how populations would spread (or not) across the mosaic of sediment textures that make up a single stream. It is impossible, however, to examine every possible bed texture so being able to characterise/summarise how movements vary with particular physical properties of bed topography and near-bed hydraulics would be advantageous. 


\section{What is the optimal design for fish passage structures?}

From an engineering perspective, river infrastructure, such as dams, weirs, and flood control facilities are essential for societal development and quality of life. However, such infrastructure also has significant negative impacts on freshwater ecosystems, particularly on populations of fish due to fragmentation of habitat when movement is impeded by physical barriers (Lucas and Baras, 2001). In England, the need to provide routes of passage past anthropogenic impediments was recognized as early as the $12^{\text {th }}$ century when a declaration was passed that barriers be provided with a "King's gap” of sufficient width to allow a wellfed three-year-old pig to stand sideways without touching either side (Montgomery, 2003). Although the design of fish passage facilities has advanced and is now viewed as an integral component of wider mitigation strategies, the success of fish passes is highly variable. In part, this reflects a tradition of designing fish passes based on an iterative "trial-and-error" approach. The effectiveness of fish passes are monitored; structures are modified to compensate for deficits until they better "fit” site-specific conditions; and eventually, acceptable levels of fish passage efficiency may be achieved. This process is inefficient, providing adequate solutions only after considerable financial cost and significant ecological impact. The development of fish passages for downstream migrating juveniles in the Columbia River provides a good illustration (Kemp et al., 2008). Moreover, this approach produces structures that are unlikely to be resilient to changes in environmental conditions including, for example, changes in discharge and temperature regimes associated with climate change.

Effective fish passage design is constrained also by a shortage of information about how fish interact with hydraulic structures which, in turn, reflects three historical biases in the 
development of fish passages. First, fish passage criteria have traditionally been biased to upstream migrating adult salmonids, with little consideration of non-salmonid species (Lucas et al., 2000; Larinier and Marmulla, 2004). Second, design criteria for fish passes are conventionally based on empirical measures of swimming capabilities obtained by forcing test fish to swim against artificial rectilinear flows in swim chambers (e.g. Brett, 1964; Jones et al.,1974; Stahlberg and Peckmann, 1987; Videler, 1993; Peake et al., 1997). There is virtually no understanding of how the behavioural component of volitional swimming influences performance under the complex fluid flows that are common in nature. Third, design of bypass systems for fish migrating downstream past hydropower dams has traditionally represented fish as neutrally buoyant particles subject only to passive transport (Cada, 2001) and devoid of behavioural responses. Overcoming these biases poses significant challenges that require consideration of non-salmonid, non-adult fish and explicit consideration of the behavioural components in volitional upstream and downstream swimming under natural flow conditions. Bias towards adult salmon is well recognized and is currently being addressed by many groups (e.g. USGS Conte Anadromous Fish Laboratory, US; International Centre for Ecohydraulic Research, UK). In general, there is considerable academic interest in the migratory performance and behavioural strategies employed by fish that exhibit alternative forms of locomotion to those of the sub-carangiform salmonids. For example, how do anguilliform fish such as eel (Anguilla anguilla) and lamprey (e.g. Lampetra spp.) that possess extremely elongated bodies negotiate structural obstacles under high energy, complex fluid flows? Flume experiments are useful tools to address gaps in our understanding of the interactions between fish locomotion and fluid dynamics but the most productive research requires effective collaboration between fish ecologists and hydraulicists. 


\section{Methodological issues}

Using flume studies, we are able to directly observe fish locomotion and behaviour under controlled conditions. Although many studies have attempted to mimic natural conditions (e.g. by providing fluvial gravel substrate, shelter, or natural photoperiod), the need for physical realism is less important when attempting to define fish response to hydraulics per se. Indeed, fish passage facilities are unnatural features (although "nature-like” bypasses attempt to replicate more natural conditions, e.g. Santos et al., 2005; Schmutz et al., 1998). It is important, however, to adequately define the fluid dynamics associated with flume walls, in-stream structures, a submerged boulder or branch, to which fish respond. Depending on the question posed, "wall effects" can provide useful conditions to assess the use of behavioural strategies to minimize energetic costs, as will be described later. An additional requirement is to ensure that hydraulic conditions are measured at an appropriate scale relative to the fish. Hence the selection of an appropriate technique (e.g. ADV, PIV, CFD) to define hydraulics is important and remains a subject of debate (as discussed above).

In many flume studies, fish are allowed a period of acclimation within the experimental arena prior to the commencement of tests. However, this is inappropriate when studying actively migrating life-stages as the "holding” of fish for any length of time may impact motivation to migrate. One potential solution, used in studies of migrating smolts (Kemp et al., 2005, 2006), is to divert fish from a fish bypass system into a flume where they encounter test conditions before being redirected to the bypass system. This removed the stresses that accompany capture, transport and handling of fish, as well as the risk that behaviour is altered by acclimation periods.

Flumes are an important tool for defining fish passage criteria because, unlike swim chambers which generally yield conservative estimates of fish swimming capabilities (Haro et al., 2004; 
Peake and Farrell, 2005; Castro-Santos, 2004, 2005), they do not inhibit performanceenhancing behaviours, such as “burst-glide” swimming (Tudorache et al., 2007). Whether derived from flumes or swim chambers, estimates obtained under relatively simple rectilinear flows may be higher than those observed under complex turbulent conditions that reduce swimming performance (e.g. Enders et al., 2003 for juvenile Atlantic salmon [Salmo salar] under experimental conditions; Lucas and Bubb, 2005 for grayling [Thymallus thymallus] in the field), emphasising the need for careful thought about the degree to which flow complexity is simulated. In the UK, there is considerable interest in anguilliform species, primarily eels as a result of declines over recent decades, but also lamprey that are protected under EU legislation. The use of flumes to define fish passage criteria for these species is currently underway in which traditional measures of swimming performance (e.g. burst or critical swimming tests; Brett, 1964; Jones et al.,1974; Stahlberg and Peckmann, 1987; Videler, 1993; Peake et al., 1997) are replaced by experiments which test the ability of fish to negotiate structural impediments, and their associated hydraulic conditions, that are encountered in the field (e.g. weirs).

For downstream migrating life-stages, the solution to the problem of assumed neutral buoyancy during a passive migration is to simply conduct tests that validate whether this is the case. Unfortunately, the design of bypass systems (and assessment of turbine configuration and operation) for smolts migrating downstream past hydropower dams often continue to be based on these assumptions; for example, in physical models to assess the impact of screens and passage through dam infrastructure (Cada, 2001). This “obligate passive migrant” paradigm was supported by fish biologists who used swim chamber data to argue that smolts were physiologically incapable of active migration due to reduced swimming capability (Thorpe and Morgan, 1978). Although flume experiments demonstrate that smolts are capable of strong sustained swimming (Peake and McKinley, 1998), the 
behaviour of downstream migrating fish has generally been ignored during fish passage design. To address this issue, experimental flumes have been used to assess Pacific salmon smolt response to simple hydraulic measures including velocity gradients (Kemp et al., 2005; 2006) and relative turbulence intensity (Kemp and Williams, 2008) by providing fish with a choice of routes that differed in hydraulic character.

Defining the response of fish to fluid dynamics is a first step to understanding the mechanisms by which decisions are made. Controlled flume experiments can also facilitate investigations to determine the modes by which information is acquired. Fish utilize a variety of senses during migration. In the near field, vision and the lateral line system are of primary importance (Giske et al., 1998). The mechanosensory lateral line is used to monitor the local hydrodynamic environment, and is sensitive to water velocity and thus important for rheotaxis (Montgomery et al., 1997; Baker and Montgomery, 1999) and the acceleration component of oscillatory water flow (Montgomery et al., 1997; 2003). Studies designed to identify the relative roles of vision and the lateral line system have often relied on experimental manipulation of the fish, e.g. temporary blinding (Pitcher et al., 1976; Partridge and Pitcher, 1980), and chemical (e.g. Karlsen and Sand, 1987; Kaus, 1987; Song et al., 1995) or physical (e.g. Montgomery et al., 1997; 2003) ablation of the lateral line submodalities. However, the destructive effects associated with these techniques could influence motivational state and consequent behaviour exhibited by the subjects. In contrast, the smolt study conducted by Kemp et al. (2006) controlled for the role of visual stimuli by comparing the results of tests conducted in the dark, using infrared illumination to facilitate direct observation, with those during periods of light. 


\section{Results, outcomes and observations}

Experiments using large flumes have provided a useful insight into the swimming performance and behaviours of non-salmonid species on which realistic fish passage criteria can be developed (e.g. Haro et al., 2004). Flume research has shown that downstream moving adult silver eels are primarily passive migrants at fine-scales, but also exhibit periods of active station maintenance and avoidance (Russon et al., in prep), and this supports field observations using radio-telemetry (Winter et al., 2006). Even in relatively shallow water, eels remain sufficiently substrate oriented so that even a small impediment, e.g. a $20 \mathrm{~cm}$ high overshot weir, can cause significant delay (Russon et al., in prep).

Assessment of lamprey swimming capability using traditional techniques provides interesting challenges as these fish use their oral disk to attach to the substrate or other structures for extended periods of rest (Kemp et al., in prep). This applies equally to the use of a flume as it does to a swim chamber. In a flume experiment in which upstream migrating river lamprey encountered either an overshot or undershot weir under three alternative discharge regimes, the exhibition of oral attachment was positively related to discharge and associated velocities (Kemp et al., in prep). This indicates a more frequent use of a "burst-attach" mode of intermittent locomotion to minimize energetic costs during upstream migration at high velocities. Further, instances of upstream progress close to the flume wall were significantly greater under high flows, possibly because the fish exploited lower velocities and reverse flow vortices to minimize energetic expenditure and enhance performance (Kemp et al., in prep). The experiments showed that river lamprey are capable of burst swimming against velocities as high as $1.6 \mathrm{~m} \mathrm{~s}^{-1}$ when motivated to pass an impediment to migration, as opposed to measures that might have been obtained by forcing fish to exhibit unnatural swimming in a chamber. 
In experiments where downstream migrating Pacific salmon smolts encountered a choice of two alternative routes of passage that were hydraulically different, they actively avoided one of the treatments. Downstream migrating smolts do not merely migrate passively, at-least at this fine scale. The smolts rejected areas associated with: 1) an abrupt acceleration of velocity where the channel is constricted laterally (Kemp et al., 2005) or vertically (Kemp et al., 2006); and 2) increased physical structure and associated hydraulic heterogeneity (Kemp and Williams, 2008). Goodwin et al. (2006) propose a conceptual model for the mechanisms that may underpin these observed responses based on the avoidance of hydraulic strain. A delay in migration as a result of consistent avoidance is likely to have significant ecological impacts, for example, as a result of increased energetic costs or predation risk.

It is interesting to note that Pacific salmon smolts were significantly more likely to pass a low head weir under lit conditions, than in the absence of visual cues during periods of darkness (Kemp and Williams, under review). Observation under infrared illumination indicated that this was a result of a behavioural shift in which the fish ceased to form schools and actively approach and "test" the weir when dark, but instead held station against the flow, presumably using the mechanosensory lateral line system to maintain a fix on the flume walls or floor. Both vision and the lateral line system are employed during schooling (Pitcher, 1979) which is generally thought to break down when visual cues are lost at low light intensities (e.g. Glass et al., 1986; Higgs and Fuiman, 1996; but see Pitcher et al., 1976; Partridge and Pitcher, 1980). This is of interest because juvenile salmonids form schools during migration (McCormick et al., 1998) and yet for many species this occurs primarily during hours of darkness (e.g. Tytler et al., 1978, but see Soloman, 1978; Moore et al., 1995). The results of the smolt experiment contradict previous suggestions that nocturnal migration reflects a passive downstream displacement when dark because fish are either unable to maintain a visual fix on surrounding features (Thorpe et al., 1988 for juvenile Atlantic salmon) or 
become disoriented (Pavlov, 1994 for subyearling Cyprinidae). Under the experimental conditions described, the smolts appeared able to utilize alternative senses to compensate for the loss of vision. This could not have been achieved in the absence of direct observation afforded by flume studies.

Today there is considerable interest in the development of robust methodologies to assess the porosity of barriers to fish migration. This will facilitate the quantification of relative benefits versus costs of removal or mitigation of barriers and enable the classification of surface waters based on their ecological status (as required by some legislations such as the Water Framework Directive in Europe). The information provided will help water resource managers prioritize restoration actions; that is, select the most appropriate barriers for mitigation or removal. To achieve this aim, experimental flume studies are an essential component of a research programme to develop generic fish passage criteria for multiple species and life-stages. A synergistic, interdisciplinary approach is needed in which ecologists and hydraulic engineers effectively define the "rules" for the mechanisms that underpin fish behaviour in response to fluid dynamics. This will aid modellers to develop appropriate tools (e.g. ELAM Numerical Fish surrogate; Goodwin et al., 2006) to describe and predict fish movement in response to environmental stimuli.

\section{Lessons and key challenges for 2020}

These examples illustrate the progress that is possible and that is being made when interdisciplinary teams work well together. Looking forward, and based partly on the discussion above, there are six general challenges for experimentalists working at the interface of fluvial geomorphology, stream ecology and hydraulic engineering that greater dialogue will usefully address. 
1. Realism, motivation and stimuli. The familiar problem for experimental geomorphologists and engineers of deciding what elements of the physical environment to exclude, which elements to include and how realistic or idealised simulated elements should be, is extended to include biological elements. Cues for animal behaviour need to be reproduced or controlled for, in order to isolate responses to the chosen experimental treatments. Handling and environmental stresses to animals must be minimised, before and during experiments. Care over these issues should extend equally to all species, i.e. fish and invertebrates, because all animals have complex neural systems and diverse sensory organs, and are likely to be stressed when handled by researchers and subjected to experimental conditions. Inevitably, incomplete understanding of what motivates subjects adds uncertainty to interpretation of the observations made. In this regard one major challenge is the development of truly interdisciplinary research where ecological and biological expertise is used to minimise these problems and a second is the promotion of fundamental empirical research on organism behaviour in natural environments so that flume effects can be identified. The traditions of utilising laboratory-based flumes and outdoor, artificial stream channels in ecological studies are important here, as are the use of within-stream flow channels (e.g. Poff and Ward, 1991; Bond and Downes, 2003; Gibbins et al., 2007) and studies that combine field and flume observations (e.g. Johnson et al., In press).

\section{Species diversity and generalisation. Morphological and behavioural diversity of} species makes it difficult or impossible to generalise the results of a studies using one species across the diverse organisms that inhabit the world's freshwaters. Biases toward favoured species (e.g. salmonid fish) amplify this problem. There have been some attempts to improve generality by classifying organisms according to their "traits" or adaptations for life in flowing water, but this is unlikely to yield useful groupings in the absence of many, rigorous empirical studies that link traits to hydraulics. Detailed experimental consideration of groups 
of animals with different morphologies and behavioural traits, for example sub-carangiform salmonids versus anguilliform fish, are a key area where hydraulicists and ecologists could collaborate fruitfully.

3. Individuality and mean response. Even within groups that are assumed to interact with hydraulic phenomena in a consistent manner, say a species, the individuality of animal behaviour cannot be ignored. This has several implications in flume modelling. First there is a need to replicate with attendant demands on resources. Replication with different individuals is essential to satisfy assumptions of statistical tests (i.e. independent observations) and because animals are capable of learning and modifying their behaviour (unless tests of learning are part of the research questions). Second, it may be unhelpful to focus solely on mean biological responses. Physical and biological scientists tend to focus on averages and view variance as an error term and an inconvenience, but the variability of animal responses may be more insightful and appropriate to some research questions. Tools such as quantile regression that explicitly recognise the importance of variability are valuable in this regard (e.g. Lancaster and Belyea; 2006).

4. Scaling considerations. Flume work with small animals can be at almost prototype scale - Froude or other scaling of physical models is not necessarily needed or plausible. Nevertheless, in all but the biggest flumes the spatial domain is restricted and two of the model's simplifications will be reduced spatial extent and reduced spatial complexity (patchiness), both of which can affect many ecological processes at population, community and ecosystem scales. Learning how to scale up results from small-experimental facilities to rivers is a further challenge.

5. Practical and technical challenges. There are a number of practical challenges that working with live animals bring to laboratory experiments: making the hydraulic 
measurements that matter (compromises between local resolution and spatial extent are particularly difficult); controlling the flume type and environment for temperature, water quality and light as well as for flow; taking care of animal welfare and ensuring that animals are securely confined; and keeping track of animals that are difficult to see because of size, lighting conditions or speed of movement. Our experience is that many of these challenges have been faced many times in experimental work and that interdisciplinary literature searches provide valuable guidance regarding many of them.

\section{Integrating laboratory experiments with field observations and numerical}

modelling. Numerical models allow simulation of systems that are otherwise inaccessible because their spatial or temporal domains are too large, because technology for making direct observations is inadequate or because the systems themselves are hypothetical constructs. Numerical modelling has a long and rich pedigree in all three disciplines. However, modelling is frequently a poor place to break into a problem in the absence of the process understanding and empirical data necessary to construct reasonable model structures (both physical and biological) and define reasonable relationships and rules. Just as the benefits of interdisciplinary work are multiplicative, so are the potential dangers of weak modelling dominated by unjustified assumptions in one area or another, or devoid of appropriate statements of uncertainty. A final challenge is to work strategically to make complementary use of field studies, physical and numerical modelling. For example: without physical modelling and empirical observations we cannot understand the fundamental processes and the interactions within and between the physical and biological spheres that numerical models should then try to simulate; data generated in physical models may be crucial for calibrating parameters in numerical models; and numerical simulations require validation using robust datasets, and physical modelling, because of control, can generate such datasets. 


\section{Acknowledgements}

SPR would like to thank the organisers and participants of Hydralab III (Lisbon, May 2007)

for encouraging him to think about these issues. SPR and JL wish to thank Tom Buffin-

Bélanger and Ian Reid for many discussions surrounding the topics covered here and for their ongoing work on the macroinvertebrate refugia project funded by NERC grant NER/B/S/2000/00697. 


\section{References}

Allan JD, Feifarek BP. 1989. Distances travelled by drifting mayfly nymphs: factors influencing return to the substrate. Journal of the North American Benthological Society 8: $322-330$.

Anderson KE, Paul AJ, McCauley E, Jackson LJ, Post JR, Nisbet RM. 2006. Instream flow needs in streams and rivers: the importance of understanding ecological dynamics. Frontiers in Ecology and the Environment 4: 309-318.

Ashmore PE. 1982. Laboratory modelling of gravel, braided stream morphology. Earth Surface Processes and Landforms 7: 201-225.

Ashworth PJ. 1996. Mid-channel bar growth and its relationship to local flow strength and direction. Earth Surface Processes and Landforms 21: 103-123.

Baker CF, Montgomery JC. 1999. Lateral line mediated rheotaxis in the Antarctic fish Pagothenia borchgrevinki. Polar Biology 21: 305-309.

Barmuta LA, McKenny CEA, Swain R. 2001. The response of lotic mayfly Nousia sp. (Ephemeroptera: Leptophlebiidae) to moving water and light of different wavelengths. Freshwater Biology 46: 567-573. DOI: 10.1046/j.1365-2427.2001.00692.x

Benda LE, Poff NL, Tague C, Palmer MA, Pizzuto J, Cooper S, Stanley E, Moglen G. 2002. How to avoid train wrecks when using science in environmental problem solving. BioScience 52: 1127-36

Bjornn TC, Kirking SC, Meehan WR. 1991. Relation of cover alterations to the summer standing crop of young salmonids in small Southeast Alaska streams. Transaction of the American Fisheries Society 120, 562-570.

Bond B. 2003. Hydrology and ecology meet - and the meeting is good. Hydrological Processes 17: 2087-2089. 
Bond NR, Downes BJ. 2003. The independent and interactive effects of fine sediment and flow on benthic invertebrate communities characteristic of small upland streams. Freshwater Biology 48: 455-465.

Brayshaw AC, Frostick LE, Reid I. 1983. The hydrodynamics of particle clusters and sediment entrainment in coarse alluvial channels. Sedimentology 30: 137-143.

Brett JR. 1964. The respiratory metabolism and swimming performance of young sockeye salmon. Journal of the Fisheries Research Board of Canada 21: 1183-1226.

Brown C, Laland K, Krause J. 2006. Fish Cognition and Behavior. Blackwells: Oxford

Buffin-Bélanger T. 2001. Structure d'un écoulement turbulent dans un cours d'eau à lit de graviers en présence d'amas de galets. Ph.D., Université de Montréal.

Buffin-Bélanger T, Reid I, Rice SK, Chandler JH, Lancaster J. 2003. A casting procedure for reproducing coarse-grained sedimentary surfaces. Earth Surface Processes and Landforms 28: 787-796. DOI: 10.1002/esp.490

Buffin-Bélanger T, Rice S, Reid I, Lancaster J. 2006. Spatial heterogeneity of near-bed hydraulics above a patch of river gravel. Water Resources Research 42: W04413. DOI:10.1029/2005WR004070

Buffington JM, Montgomery DR. 1999. A procedure for classifying textural facies in gravelbed rivers. Water Resources Research 35: 1904-1914.

Butler DR, Malanson GP. 2005. The geomorphic influences of beaver dams and failures of beaver dams. Geomorphology 71: 48-60.

Cada GF. 2001. The development of advanced hydroelectric turbines to improve fish passage survival. Fisheries 26: 14-23.

Castro-Santos T. 2004. Quantifying the combined effects of attempt rate and swimming capacity on passage through velocity barriers. Canadian Journal of Fisheries and Aquatic Sciences 61: 1602-1615. 
Castro-Santos T. 2005. Optimal swim speeds for traversing velocity barriers: an analysis of volitional high-speed swimming behavior of migratory fishes. Journal of Experimental Biology 208: 421-432.

Ciborowski JJH, Corkum LD. 1980. Importance of behaviour to the re-establishment of drifting Ephemeroptera. In Advances in Ephemeropteran Biology, JF Flannagan, KE Marshall (eds). Plenum Press: New York; 321-330.

Clifford NJ. 1996. Morphology and stage-dependent flow structure in a gravel-bed river. In Coherent Flow Structures in Open Channels, P Ashworth, JL Best, SJ Bennett, SJ McLelland (eds). Wiley: Chichester; 545-566.

Cotton JA, Wharton G, Bass JAB, Heppell CM, Wotton RS. 2006. The effects of seasonal changes to in-stream vegetation cover on patterns of flow and accumulation of sediment. Geomorphology 77 : 320-334.

Crowder LB, Cooper WE. 1982. Habitat structural complexity and the interaction between bluegills and their prey. Ecology, 63: 1802-1813.

Dancey CL, Balakrishnan M, Diplas P, Papanicolaou AN. 2000. The spatial inhomogeneity of turbulence above a fully rough, packed bed in open channel flow, Experiments in Fluids 29: $402-410$.

Davidsen J, Svenning M-A, Orell P, Yoccoz N, Dempson JB, Niemelä E, Klemetsen A, Lamberg A, Erkinaro J. 2005. Spatial and temporal migration of wild Atlantic salmon smolts determined from a video camera array in the sub-Arctic River Tana. Fisheries research 74: 210-222.

Death RG. 2008. Effects of floods on aquatic invertebrate communities. In Aquatic Insects: Challenges to Populations, Lancaster J, Briers RA (eds). CAB International: Wallingford, UK; 103-121. 
Diehl S. 1988. Foraging efficiency of three freshwater fishes: effects of structural complexity and light. Oikos 53, 207-214.

Dodds GS, Hisaw FL. 1924. Ecological studies of aquatic insects. I. Adaptations of mayfly nymphs to swift streams. Ecology 5: 137-148.

Enders EC, Boisclair D, Roy AG. 2003. The effect of turbulence on the cost of swimming for juvenile Atlantic salmon (Salmo salar). Canadian Journal of Fisheries and Aquatic Sciences 60: 1149-1160.

Everest FH, Chapman DW. 1972. Habitat selection and spatial interaction by juvenile chinook salmon and steelhead trout in two Idaho streams. Journal of the Fisheries Research Board of Canada 29: 91-100.

Fausch K, White R. 1981. Competition between brook trout (Salvelinus fontinalis) and brown trout (Salmo trutta) for positions in a Michigan stream. Canadian Journal of Fisheries and Aquatic Sciences 38: 1220-227.

Ferguson R. 2007. Flow resistance equations for gravel- and boulder bed streams. Water Resources Research 43: W05427, doi:10.1029/2006WR005422

Frissell CA, Nawa RK. 1992. Incidence and causes of physical failure of artificial habitat structures in streams of Western Oregon and Washington. North American Journal of Fisheries Management 12: 182-197.

Gibbins CN, Vericat D, Batalla RJ, Gomez CM. 2007. Shaking and moving: low rates of sediment transport trigger mass drift of stream invertebrates. Canadian Journal of Fisheries and Aquatic Sciences 64: 1-5.

Giller PS, Sangpraduh N, Towney H. 1991. Catastrophic flooding and macroinvertebrate community structure. Verhandlungen der Internationalen Vereingung fur Theoretische und Angewandte Limnologie 24: 1724-1729. 
Giske J, Huse G, Fiksen O. 1998. Modelling spatial dynamics of fish. Reviews in Fish Biology and Fisheries 8: 57-91.

Glass CW, Wardle CS, Mojsiewicz WR. 1986. A light intensity threshold for schooling in the Atlantic mackerel, Scomber scombrus. Journal of Fish Biology 29: 71-81.

Goodwin RA, Nestler JM, Anderson JJ, Webber LJ, Loucks DP. 2006. Forecasting 3-D fish movement behavior using an Eulerian-Lagrangian-agen method (ELAM). Ecological Modelling 192: 197-223.

Gottesfeld AS, Hassan MA, Tunnicliffe JF, Poirier RW. 2004. Sediment dispersion in salmon spawning streams: the influence of floods and salmon redd construction. Journal of the American Water Resources Association 40: 1071-1086.

Griffiths S, Armstrong J. 2000. Differential responses of kin and nonkin salmon to patterns of water flow: does recirculation influence aggression? Animal Behaviour 59: 1019-1023. Hannah DM, Wood PJ, Sadler JP. 2004. Ecohydrology and hydroecology: A 'new paradigm'? Hydrological Processes, 18: 3439-3445.

Hannah DM, Sadler JP, Wood PJ. 2007. Hydroecology and ecohydrology: Challenges and future prospects. In Hydroecology and Ecohydrology: Past, Present and Future, Wood PJ, Hannah DM, Sadler JP (eds). John Wiley \& Sons: Chichester; 421-429.

Haro A, Castro-Santos T, Noreika J, Odeh M. 2004. Swimming performance of upstream migrant fishes in open-channel flow: a new approach to predicting passage through velocity barriers. Canadian Journal of Fisheries and Aquatic Sciences 61: 1591-1601. Hart DD, Finelli CM. 1999 Physical-biological coupling in streams: The pervasive effects of flow on benthic organisms. Annual Review of Ecology and Systematics 30: 363-395.

Higgs DM, Fuiman LA. 1996. Light intensity and schooling behaviour in the larval gulf menhaden. Journal of Fish Biology 48: 979-991. 
Holomuzki JR, Biggs BJF. 1999. Distributional responses to flow disturbance by a streamdwelling snail. Oikos 87: 36-47.

Hora SL. 1922. Structural modifications in fish of mountain torrents. Records of the Indian Museum 24: 31-61.

Hynes HBN. 1970. The Ecology of Running Waters. Liverpool University Press: Liverpool.

Iseya F, Ikeda K. 1987. Pulsations in bedload transport rates induced by longitudinal sediment sorting; a flume study using sand gravel mixtures. Geografiska Annaler 69A: 15-27.

Jenkins TM. 1969. Social structure, position choice and micro-distribution of two trout species (Salmo trutta and Salmo gairdneri) resident in mountain streams. Animal Behaviour Monographs 2, 56-123.

Johnson M, Reid I, Rice SP, Wood PJ. In press. Stabilisation of fine gravels by net-spinning caddisfly larvae. Earth Surface Processes and Landforms.

Jones CG, Lawton JH, Shachak M. 1994. Organisms as ecosystem engineers. Oikos 69: 373386.

Jones DR, Kiceniuk JW, Bamford OS. 1974. Evaluation of the swimming performance of several fish species from the Mackensie River. Journal of the Fisheries Research Board Canada 31: 1641-1647.

Jonsson PR, van Duren LA, Amielh M, Asmus R, Aspden RJ, Daunys D, Friedrichs M, Friend PL, Olivier F, Pope N, Precht E, Sauriau P-G, Schaaff E. 2006. Making water flow: A comparison of the hydrodynamic characteristics of 12 different benthic biological flumes. Aquatic Ecology 40: 409-438.

Karlsen HE, Sand O. 1987. Selective and reversible blocking of the lateral line in freshwater fish. Journal of Experimental Biology 133: 249-262.

Kaus S. 1987. The effect of aminoglycoside antibiotics on the lateral line organ of Apolocheilus lineatus (Cyprinodontidae). Acta Oto-Laryngologica 103: 291-298. 
Kemp PS, Gessel MH, Williams JG. 2005. Fine-scale behavioral responses of Pacific salmonid smolts as they encounter divergence and acceleration of flow. Transactions of the American Fisheries Society 134: 390-398.

Kemp PS, Gilvear DJ, Armstrong JD. 2006. Variations in performance reveals dischargerelated energy costs for foraging Atlantic salmon (Salmo salar) parr. Ecology of Freshwater Fish 15: 565-571.

Kemp PS, Gessel MH, Sandford BP, Williams JG. 2006. The behaviour of Pacific salmonid smolts during passage over two experimental weirs under light and dark conditions. River Research and Applications 22: 429-440.

Kemp PS, Williams JG. 2008. Response of migrating Chinook salmon (Oncorhynchus tshawytscha) smolts to in-stream structure associated with culverts. River Research and Applications 24: 571-579.

Kemp PS, Gessel MH, Williams JG. 2008. Response of downstream migrant juvenile Pacific salmonids to accelerating flow and overhead cover. Hydrobiologia 609: 205-207.

Kirchner JW, Dietrich WE, Iseya F, Ikeda H. 1990. The variability of critical shear stress, friction angle, and grain protrusion in water-worked sediments. Sedimentology 37: 647672.

Kirkbride AD. 1993. Observation of the influence of bed roughness on turbulence structure in depth limited flows over gravel beds. In Turbulence: Perspectives on Flow and Sediment Transport, Clifford NJ, French JR, Hardisty J (eds). Wiley: Chichester; 185196.

Lake PS. 2000. Disturbance, patchiness, and diversity in streams. Journal of the North American Benthological Society 19: 573-592.

Lake PS, Bond NR, Reich P. 2007. Linking ecological theory with stream restoration. Freshwater Biology 52: 597-613. 
Lamarre H, Roy AG. 2005. Reach scale variability of turbulent flow characteristics in a gravel-bed river. Geomorphology 68: 95-113

Lancaster J. 1999. Small scale movements of lotic macroinvertebrates with variations in flow. Freshwater Biology 41: 605-619.

Lancaster J. 2000. Geometric scaling of microhabitat patches and their efficacy as refugia during disturbance. Journal of Animal Ecology 69: 442-457.

Lancaster J. 2008. Movement and dispersion of insects in stream channels: What role does flow play? In Aquatic Insects: Challenges to Populations, Lancaster J, Briers RA (eds). CAB International: Wallingford, UK; 139-157.

Lancaster J, Hildrew AG. 1993. Flow refugia and the microdistribution of lotic macroinvertebrates. Journal of the North American Benthological Society 12: 385-393. Lancaster J, Hildrew AG. 1993. Characterizing in-stream flow refugia. Canadian Journal of Fisheries and Aquatic Sciences 50: 1663-1675.

Lancaster J, Belyea LR. 1997. Nested hierarchies and scale-dependence of mechanisms of flow refugium use. Journal of the North American Benthological Society 16: 221-238. Lancaster J, Belyea LR. 2006. Defining the limits to local density: alternative views of abundance-environment relationships. Freshwater Biology 51: 783-796. DOI: 10.1111/j.1365-2427.2006.01518.x

Lancaster J, Buffin-Bélanger T, Reid I, Rice S. 2006. Flow- and substratum-mediated movement by a stream insect. Freshwater Biology 51: 1053-1069. DOI:10.1111/j.13652427.2006.01554.x

Lancaster J, Downes BJ, Glaister A. in review a. Interacting environmental gradients, tradeoffs and reversals in the abundance-environment relationships of stream insects: when flow is unimportant. Marine and Freshwater Research. 
Lancaster J., Downes BJ, Arnold A. in review b. Environmental constraints on oviposition may limit density of a stream insect at multiple scales. Ecology

Lane SN, Hardy RJ, Elliott L, Ingham DB. 2004. Numerical modeling of flow processes over gravelly surfaces using structured grids and a numerical porosity treatment. Water Resources Research 40:W01302.

Larinier M, Marmulla G. 2004. Fish passes: types, principles and geographic distribution: an overview. Proceedings of the second international symposium on the management of large rivers for fisheries. Vol. II. Sustaining livelihoods and biodiversity in the New Millennium. 11-14 ${ }^{\text {th }}$ February, 2003, Phnom Penh, Kingdom of Cambodia. Welcomme RL, Petr T (eds).

Lawless M, Robert A. 2001. Three-dimensional flow structure around small-scale bedforms in a simulated gravel environment. Earth Surface Processes and Landforms 26: 507522.

Lewis DM, Pedley TJ. 2001. The influence of turbulence on plankton predation strategies. Journal of Theoretical Biology 210: 347-365.

Liao JC. 2007. A review of fish swimming mechanics and behaviour in altered flows. Philosophical Transactions of the Royal Society, Biological Science 362, 1973-93. Lucas MC, Bubb DH. 2005. Seasonal movements and habitat use of grayling in the UK. Science Report: SC030210/SR Environment Agency / Grayling Research Trust.

Lucas MC, Mercer T, McGinty S, Armstrong JD. 2000. Development and evaluation of a flatbed passive integrated transponder detection system for recording movement of lowland river fishes through a baffled pass. In Advances in Fish Telemetry, Moore A, Russel I (eds). CEFAS: Suffolk; 117-127.

Lucas MC, Baras E. 2001. Migration of Freshwater Fishes. Blackwells: Oxford. 
Matthaei CD, Uehlinger U, Frutiger A. 1997. Response of benthic invertebrates to a natural versus experimental disturbance in a Swiss prealpine river. Freshwater Biology 37: 6177.

MacKenzie BR, Kiorboe T. 1995. Encounter rates and swimming behaviour of pauste-travel and cruise larval fish predators in calm and turbulent laboratory environment. Limnology and Oceanography 40: 1278-1289.

McCormick SD, Hansen LP, Quinn TP, Saunders RL. 1998. Movement, migration, and smolting of Atlantic salmon (Salmo salar). Canadian Journal of Fisheries and Aquatic Sciences 55: 77-92.

McLean SR, Nikora VI, Coleman SE. 2007. Double-averaged velocity profiles over fixed dune shapes. Acta Geophysica 56: 669-697.

Millar RG. 2000. Influence of bank vegetation on alluvial channel patterns, Water Resources Research 36: 1109-1118.

Montgomery DR. 2003. King of fish: the thousand-year run of salmon. Westview Press, Boulder CO.

Montgomery JC, Baker CF and Carton AG. 1997. The lateral line can mediate rheotaxis is fish. Nature 389: 960-963.

Montgomery JC, McDonald F, Baker CF, Carton AG, Ling N. 2003 Sensory integration in the hydrodynamic world of rainbow trout. Proceedings of the Royal Society, B 270 (S2): 195-197.

Moore A, Potter ECE, Milner NJ, Bamber S. 1995. The migratory behaviour of wild Atlantic salmon (Salmo salar L) smolts in the estuary of the River Conwy, North Wales. Canadian Journal of Fisheroes and Aquatic Sciences 52: 1923-1935.

Naiman RJ. 1999. A perspective on interdisciplinary science. Ecosystems 2: 292-295. 
Nestler JM, Goodwin RA, Smith DL and Anderson JJ. 2007. A mathematical and conceptual framework for ecohydraulics. In Hydroecology and Ecohydrology: Past, Present and Future, Wood PJ, Hannah DM, Sadler JP (eds). John Wiley \& Sons: Chichester; 205224

Nielsen A. 1951. Is dorsoventral flattening of the body an adaptation to torrentia life? Verhandlungen der Internationalen Vereingung für Theoretische und Angewandte Limnologie 11: 264-267.

Nikora VI, Goring DG, Biggs BJF. 1998. On gravel-bed roughness characterization. Water Resources Research 34: 517-527.

Nowell AR, Church M. 1979. Turbulent flow in a depth-limited boundary layer. Journal of Geophysical Research 84: 4816-4824.

Nowell ARM, Jumars PA. 1987. Flumes - theoretical and experimental considerations for simulation of benthic environments. Oceanography and Marine Biology Annual Review 25: $91-112$.

Novak P, Cábelka J. 1981. Models in Hydraulic Engineering: Physical Principles and Design Applications. Pitman Publishing: London.

Oldmeadow DF. 2005. Persistence of stream invertebrate populations during hydraulic disturbances. PhD Thesis, University of Edinburgh.

Oldmeadow DF, Church M. 2006. A field experiment on riverbed stabilisation by gravel structures. Geomorphology 78: 335-350.

Olson AD and West JR. 1989. Evaluation of Instream Fish Habitat Restoration Structures in Klamath River Tributaries, 1988/1989. Annual Report for Interagency Agreement 1416-0001-89508. US Forest Service. Pacific Southwest Region. Klamath National Forest. Yreka, CA. 36 pp. 
Palmer MA, Arsenburger P, Martin AP, Denman DW. 1996. Disturbance and patch-specific responses: the interactive effects of woody debris dams on lotic invertebrates. Oecologia 105: $247-257$.

Palmer MA, Ambrose RF, Poff NL. 1997. Ecological theory and community restoration ecology. Restoration Ecology 5: 291-300.

Palmer MA, Bernhardt ES. 2006. Hydroecology and river restoration: Ripe for research and synthesis. Water Resources Research 42, W03S07, doi:10.1029/2005WR004354.

Paola C, Seal R. 1995. Grain size patchiness as a cause of selective deposition and downstream fining. Water Resources Research 31: 1395-1407.

Partridge BL, Pitcher TJ. 1980. The sensory basis of fish schools: relative roles of lateral line and vision. Journal of Comparative Physiology 135: 315-325.

Pavlov DS. 1994. The downstream migration of young fishes in rivers: mechanisms and distribution. Folia Zoologica 43: 193-208.

Peakall J, Ashworth P, Best JL. 1996. Physical modelling in fluvial geomorphology: principles, applications and unresolved issues. In The Scientific Nature of Geomorphology, Rhoads BL and Thorn CE (eds). John Wiley \& Sons: Chichester; 221253

Peake S, McKinley RS. 1998. A re-evaluation of swimming performance in juvenile salmonids relative to downstream migration. Canadian Journal of Fisheries and Aquatic Sciences 55: 682-687.

Peake SJ, Farrell AP. 2005. Postexercise physiology and repeat performance behaviour of free-swimming smallmouth bass in an experimental raceway. Physiological and Biochemical Zoology 78: 801-807. 
Peake S, McKinley RS, Scruton DA. 1997. Swimming performance of various freshwater Newfoundland salmonids relative to habitat selection and fishway design. Journal of Fish Biology 51: 710-723.

Peckarsky BL, Kerans BL, Taylor BW, McIntosh AR. 2008. Predator effects on prey population dynamics in open systems. Oecologia 156: 431-440. DOI: 10.1007/s00442008-1004-3

Pitcher TJ. 1979. Sensory information and organization of behaviour in a shoaling cyprinid fish. Animal Behaviour 27: 126-149.

Pitcher TJ, Partridge BL, Wardle CS. 1976. A blind fish can school. Science 194: 963-965.

Poff NL, Ward JV. 1991. Drift responses of benthic macroinvertebrates to experimental streamflow variation in a hydrologically stable stream. Canadian Journal of Fisheries and Aquatic Sciences 48: 1926-1936.

Rader RB. 1997. A functional classification of the drift: traits that influence invertebrate availability to salmonids. Canadian Journal of Fisheries and Aquatic Sciences 54: 1211-1234.

Raupach MR, Antonia RA, Rajagopalan S. 1991. Rough-wall turbulent boundary layers. Applied Mechanics Reviews 44: 1-25.

Rempel LL, Richardson JS, Healey MC. 1999. Flow refugia for benthic macroinvertebrates during flooding of a large river. Journal of the North American Benthological Society 18: $34-48$.

Rice S, Buffin-Bélanager T, Lancaster J, Reid I. 2007. Movements of a macroinvertebrate (Potamophylax latipennis) across a gravel-bed substrate: effects of local hydraulics and micro-topography under increasing discharge. In Gravel-bed Rivers: From Process Understanding to River Restoration, Habersack H, Hoey T, Piegay H, Rinaldi M (eds). Elsevier BV: Amsterdam; 637-660. 
Riley SC, Fausch KD. 1995. Trout population response to habitat enhancement in six northern Colorado streams. Canadian Journal of Fisheries and Aquatic Sciences 52: 34-53.

Robertson AL, Lancaster J, Hildrew AG. 1995. Stream hydraulics and the distribution of microcrustacea: a role for refugia? Freshwater Biology 33: 469-484.

Roni P, Quinn TP. 2001. Density and size of juvenile salmonids in response to placement of large woody debris in western Oregon and Washington streams. Canadian Journal of Fisheries and Aquatic Sciences 58: 282-292.

Santos JM, Ferreira MT, Godinho FN, Bochechas J. 2005. Efficacy of a nature-like bypass channel in a Portuguese lowland river. Journal of Applied Icthyology 21: 381-388.

Savino JF, Stein RA. 1982. Predator-prey interaction between largemouth bass and bluegills as influenced by simulated, submerged vegetation. Transactions of the American Fisheries Society 111: 255-266.

Schmutz S, Giefing C, Wiesner C. 1998. The efficiency of a nature-like bypass channel for pike-perch (Stizostedion lucioperca) in the Marchfeldkanalsystem. Hydrobiologia 371372: 355-360.

Sharpe AK. 2002. An investigation of the factors and processes that influence the distribution of hydrospychid caddisfly larvae in upland streams in Southeastern Australia. $\mathrm{PhD}$ Thesis, University of Melbourne.

Slaymaker O, 1981. Geomorphic field experiments: inventory and prospect. Transactions of the Japanese Geomorpological Union 2: 159-170.

Smith JD, McLean SR. 1977. Spatially averaged flow over a wavy surface. Journal of Geophysical Research 83: 1735-1746.

Solomon DJ. 1978. Some observations on smolt migration in a chalkstream. Journal of Fish Biology 12: 571 -574. 
Song J, Hong YY, Popper AN. 1995. Damage and recover of hair cells in fish canal (but not superficial) neuromasts after gentamicin exposure. Hearing Research 91: 63-71.

Southard JB, Boguchwal LA, Romea RD. 1980. Test of scale modelling of sediment transport in steady unidirectional flow. Earth Surface Processes 5:17 - 23

Stahlberg S, Peckmann P. 1987. The critical swimming speed of small teleost fish species in a flume. Archiv fur Hydrobiologie 110: 179-193.

Stamhuis EJ, Videler JJ, van Duren LA, Müller UK. 2008. Applying digital particle image velocimetry to animal generated flows: Traps, hurdles and cures in mapping steady and unsteady flows in Re regimes between $10^{-1}$ and $10^{5}$. Experiments in Fluids 33: 801-813.

Statzner B, Holm TF. 1982. Morphological adaptations of benthic invertebrates to stream flow - an old question studied by means of a new technique (laser Doppler anemometry). Oecologia 53: 290-292.

Steinmann P. 1907. Die Tierwelt der Gebirgsbäche. Eine faunistisch-biologische Studie. Annales de Biologie Lacustre 2: 30-150.

Steinmann P. 1908. Die Tierwelt der Gebirgsbäche. Archiv für Hydrobiologie 35: 266-273.

Tal M, Paola C. 2007. Dynamic single-thread channels maintained by the interaction of flow and vegetation. Geology 35: 347-350.

Thompson DM, Stull GN. 2002. The development and historic use of habitat structures in channel restoration in the United States: The grand experiment in fisheries management. Geographie physique et Quaternaire 56: 45-60.

Thorpe JE, Morgan RIG. 1978. Periodicity in Atlantic salmon Salmo salar L. smolt migration. Journal of Fish Biology 12: 541-548.

Thorpe JE, Morgan RIG, Pretswell D, Higgins PJ. 1988. Movement rhythms in juvenile Atlantic salmon, Salmo salar L. Journal of Fish Biology 33: 931-940. 
Todd-Burley, NR. 2007. An experimental study of the transport pathways of individual bedload clasts over a gravel-bed substrate. PhD thesis, Loughborough University. Townsend CR. 1989. The patch dynamics concept of community stream ecology. Journal of the North American Benthological Society 8: 36-50.

Tudorache C, Viaenen P, Blust R, De Boeck G. 2007. Longer flumes increase critical swimming speeds by increasing burst-glide swimming duration in carp Cyprinus carpio, L. Journal of Fish Biology 71: 1630-1638.

Tytler P, Thorpe JE, Shearer WM. 1978. Ultransonic tracking of the movement of Atlantic salmon smolts (Salmo salar L) in the estuaries of two Scottish rivers. Journal of Fish Biology 12: 575-586.

USGS/ESA. United States Geological Survey, Ecological Society of America. 1998. Summary Report of the Workshop on Enhancing Integrated Science. Reston (VA): US Geological Survey (5 ${ }^{\text {th }}$ August 2008; http://www.usgs.gov/integrated_science/)

Van Zyll de Jong MC, Cowx IG, Scruton DA. 1997. An evaluation of instream habitat restoration techniques on salmonid populations in a Newfoundland stream. Regulated Rivers: Research and Management 13, 603-614.

Videler JJ. 1993. Fish Swimming. Chapman and Hall: London, 260 pp.

Vogel S. 1981. Life in moving fluids. Princeton University Press: Princeton.

Weissenberger J, Spatz H-C, Emanns A, Schwoerbel J. 1991. Measurement of lift and drag forces in the $\mathrm{mN}$ range experienced by benthic arthropods at flow velocities below 1.2 $\mathrm{m} \mathrm{s}^{-1}$. Freshwater Biology 25: 21-31.

Welch HE. 1976. Ecology of Chironomidae (Diptera) in a polar lake. Journal of the Fisheries Research Board of Canada 33: 227-245.

Wilzbach MA. 1990. Nonconcordance of drift and benthic activity in Baetis. Limnology and Oceanography 35: 945-952. 
Winter HV, Jansen HM, Bruijs MC. M. 2006. Assessing the impact of hydropower and fisheries on downstream migrating silver eel, Anguilla anguilla, by telemetry in the River Meuse. Ecology of Freshwater Fish 15: 221-228.

Young WJ. 1992. Clarification of the criteria used to identify near-bed flow regimes.

Freshwater Biology 28: 383-391. 